\title{
Optimization of X-ray microplanar beam radiation therapy for deep-seated tumors by a simulation study
}

\author{
Kunio Shinohara ${ }^{\mathrm{a}, *}$, Takeshi Kondoh ${ }^{\mathrm{b}, \mathrm{c}}$, Nobuteru Nariyama ${ }^{\mathrm{d}}$, Hajime Fujita ${ }^{\mathrm{a}}$, \\ Masakazu Washio a and Yukimasa Aoki ${ }^{\mathrm{e}}$ \\ ${ }^{a}$ Research Institute for Science and Engineering, Waseda University, Shinjuku-ku, Tokyo, Japan \\ ${ }^{\mathrm{b}}$ Department of Neurosurgery, Kobe University Graduate School of Medicine, Kobe-shi, Hyogo, Japan \\ 'Shinsuma General Hospital, Kobe-shi, Hyogo, Japan \\ ${ }^{\mathrm{d}}$ Japan Synchrotron Radiation Research Institute, Sayo-gun, Hyogo, Japan \\ ${ }^{\mathrm{e}}$ Medical Corporation YUKOUKAI Clinic, Funabashi-shi, Chiba, Japan
}

\section{Received 14 September 2013}

Revised 10 March 2014

Accepted 16 March 2014

\begin{abstract}
A Monte Carlo simulation was applied to study the energy dependence on the transverse dose distribution of microplanar beam radiation therapy (MRT) for deep-seated tumors. The distribution was found to be the peak (in-beam) dose and the decay from the edge of the beam down to the valley. The area below the same valley dose level (valley region) was decreased with the increase in the energy of X-rays at the same beam separation. To optimize the MRT, we made the following two assumptions: the therapeutic gain may be attributed to the efficient recovery of normal tissue caused by the beam separation; and a key factor for the efficient recovery of normal tissue depends on the area size of the valley region. Based on these assumptions and the results of the simulated dose distribution, we concluded that the optimum X-ray energy was in the range of 100-300 keV depending on the effective peak dose to the target tumors and/or tolerable surface dose. In addition, we proposed parameters to be studied for the optimization of MRT to deep-seated tumors.
\end{abstract}

Keywords: Microbeam radiation therapy, X-rays, Monte Carlo simulation, transverse dose distribution, energy dependence

\section{Introduction}

Microplanar beam radiation therapy (MRT) $[1,2]$ is based on earlier findings that tissue that has had damage induced by a narrow beam of radiation recovers more efficiently than when damage is induced by a broad beam [3,4]. Slatkin et al. [5] proposed an MRT to treat brain tumors and confirmed that normal tissue has extremely high tolerance to microplanar beam X-rays [6]. Laissue et al. [7] demonstrated that MRT is effective in increasing the life span of rats bearing brain tumors, and since then, many results for

\footnotetext{
${ }^{*}$ Corresponding author: Kunio Shinohara, Research Institute for Science and Engineering, Waseda University, 3-4-1 Okubo, Shinjuku-ku, Tokyo 169-8555, Japan. Tel.: +81 35286 3093; E-mail: kshino-tky@umin.net. 


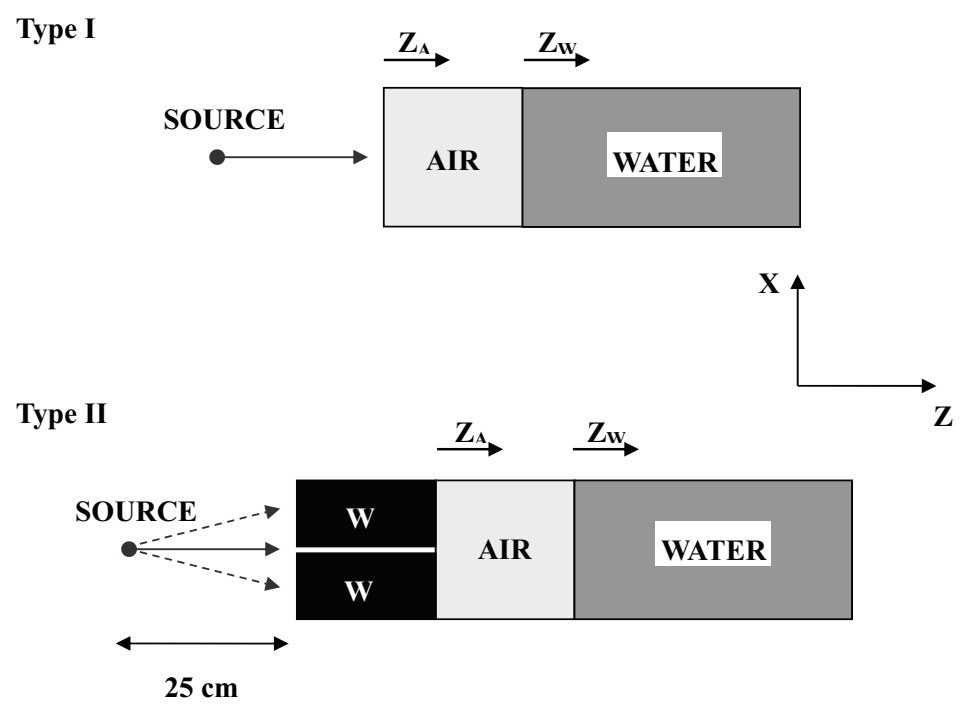

Fig. 1. Experimental setup for the calculation of absorbed dose distribution. Side views perpendicular to the propagation of $\mathrm{X}$-rays (from left to right) are illustrated. Type I: Non-divergent X-rays. Type II: Non-divergent X-rays with a single slit. $Z_{A}$ : Depth of air layer. $Z_{W}$ : Depth of water layer. The source was placed at $25 \mathrm{~cm}$ in front of the tungsten (W) slit collimator (Type II). The X-rays between the source and the air layer (Type I) or collimator (Type II) was assumed to be in a vacuum to simplify the calculation. Broken lines in Type II illustrate the conical beam.

synchrotron radiation have been accumulated with regards to its sparing effects on normal tissue [8-12] and therapeutic effects in tumor bearing animals [13-23].

MRT is a spatially fractionated radiation therapy with parallel beams of mainly $25-50 \mu \mathrm{m}$ beam width and 100-500 $\mu$ m center-to-center separation, at a peak dose of 100-600 (usually $\geqslant 300$ ) Gy from one direction or orthogonally arranged multiple directions of a single shot from each direction. Animal studies have been performed with synchrotron radiation with a mean energy of approximately $100 \mathrm{keV}$ or less.

However, to apply this method to human therapy, higher X-ray energies than those used in animal studies are preferred, because human tumors are often deep-seated, such that external low-energy X-rays are markedly decreased and the radiation effects on normal tissues in front of the tumors may become serious before delivery of the therapeutic dose. Prezado et al. [24] found that the energy to optimize the peak-to-valley ratio is $375 \mathrm{keV}$ in a mini-beam radiation therapy. However, as for spatially fractionated radiation therapy, a narrow microbeam is more effective than a wide beam [22]. In the current work, we applied a Monte Carlo simulation to study the dose distribution of MRT with respect to X-ray energy and proposed an optimized MRT for deep-seated tumors.

\section{Methods}

\subsection{Evaluation of transverse dose distribution}

The PENELOPE code [25] was used for a Monte Carlo simulation of the estimation of the transverse dose distribution profile for the following three types of X-ray beams: (1) non-divergent X-rays with a cross section of $1 \mathrm{~mm} \times 20 \mu \mathrm{m}$ (directions $\mathrm{Y} \times \mathrm{X}$, see Fig. 1) or $1 \mathrm{~mm} \times 50 \mu \mathrm{m}$; (2) non-divergent $\mathrm{X}$-rays with a cross section of $1 \mathrm{~mm} \times 1 \mathrm{~mm}$ in coming on a $50 \mu \mathrm{m}$-wide single-slit collimator defining 


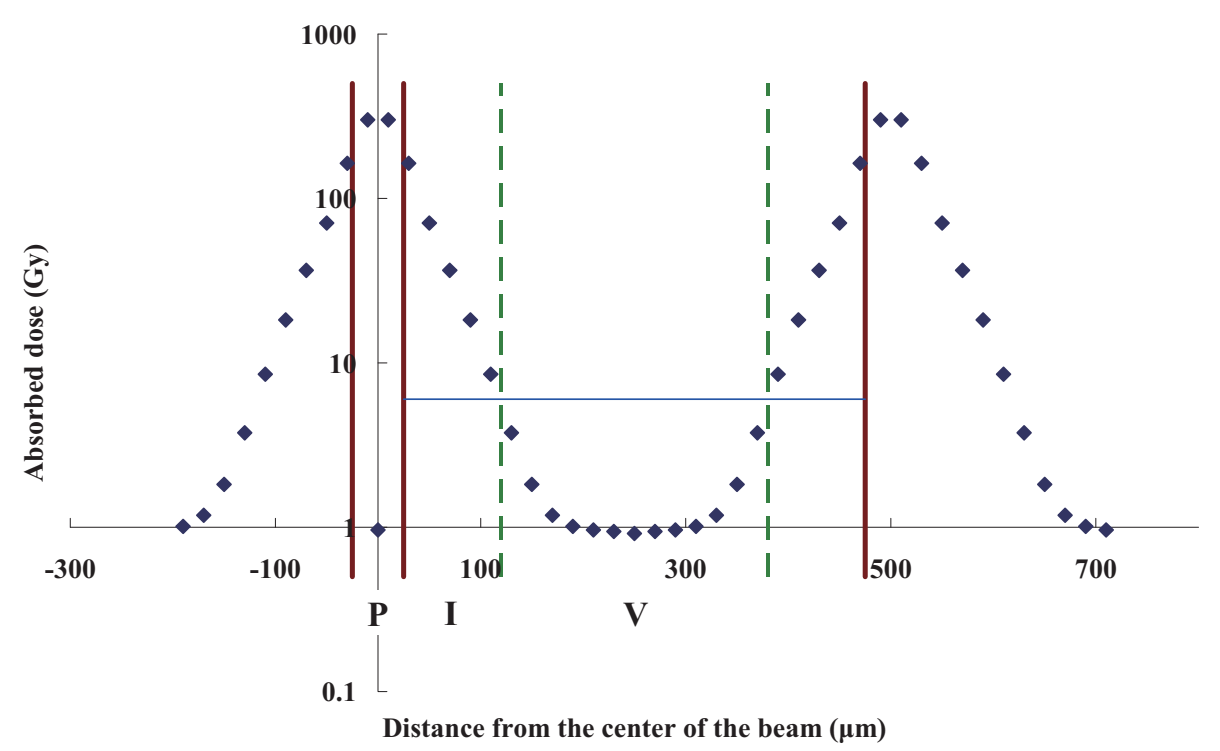

Fig. 2. Transverse dose distribution at the surface of the water. The profile represents the case when the X-ray energy, beam width, beam separation and peak dose were $250 \mathrm{keV}, 50 \mu \mathrm{m}, 500 \mu \mathrm{m}$, and $300 \mathrm{~Gy}$, respectively. Blue (solid horizontal) line shows the 6 Gy level. P, I, and V correspond to the peak zone, intermediate zone and valley zone, respectively. Brown (solid vertical) lines or green (broken vertical) lines show the borders between the P- and I-zone, and I- and V-zone, respectively. (Colours are visible in the online version of the article; http://dx.doi.org/10.3233/XST-140434)

the X direction; and (3) conical X-ray beam (4 mrad divergence) with a 20 or $50 \mu$ m-wide single-slit collimator. The collimator was composed of two tungsten (W) blocks of $10 \mathrm{~cm}$-thick (Z-axis) and $5 \mathrm{~cm}$ high (X-axis). In case (3), the beam size was $1 \mathrm{~mm}$ in diameter at the entrance of the collimator to determine a beam size at its exit to be $1 \mathrm{~mm} \times 20 \mu \mathrm{m}(\mathrm{Y} \times \mathrm{X})$ or $1 \mathrm{~mm} \times 50 \mu \mathrm{m}$. The $20 \mathrm{~cm}$ water phantom was placed behind the collimator in direct contact $(0 \mathrm{~cm})$ or at $40 \mathrm{~cm}$ or $100 \mathrm{~cm}$ in the air layer away from the collimator. Figure 1 illustrates the simulation arrangements. In this work, uniform distribution of the beam is assumed and the number of primary photon was $\sim 2 \times 10^{9}$ in all of the calculations.

\subsection{Assumptions for the analysis of transverse dose distribution profile}

To analyze the simulation results, we made the following assumptions: the therapeutic gain may be attributed to the efficient recovery of normal tissue caused by the beam separation and a key factor in the efficient recovery of normal tissue depends on the area size of the valley region. Figure 2 illustrates the separation of area proposed for the analysis of the MRT. The transverse dose profile is divided into three regions: the P-zone for the peak dose region corresponding to beam path, the V-zone for the valley dose region of absorbed dose below $6 \mathrm{~Gy}$, and the I-zone for the area between the P-and V-zones.

\section{Results}

\subsection{Comparison of the transverse dose distribution}

Figures $3 \mathrm{a}$ to $3 \mathrm{~g}$ show the comparison of $\mathrm{X}$-ray dose distribution for X-ray energies, beam structures, and different positions of the water phantom. For the non-divergent X-rays, no difference in the 


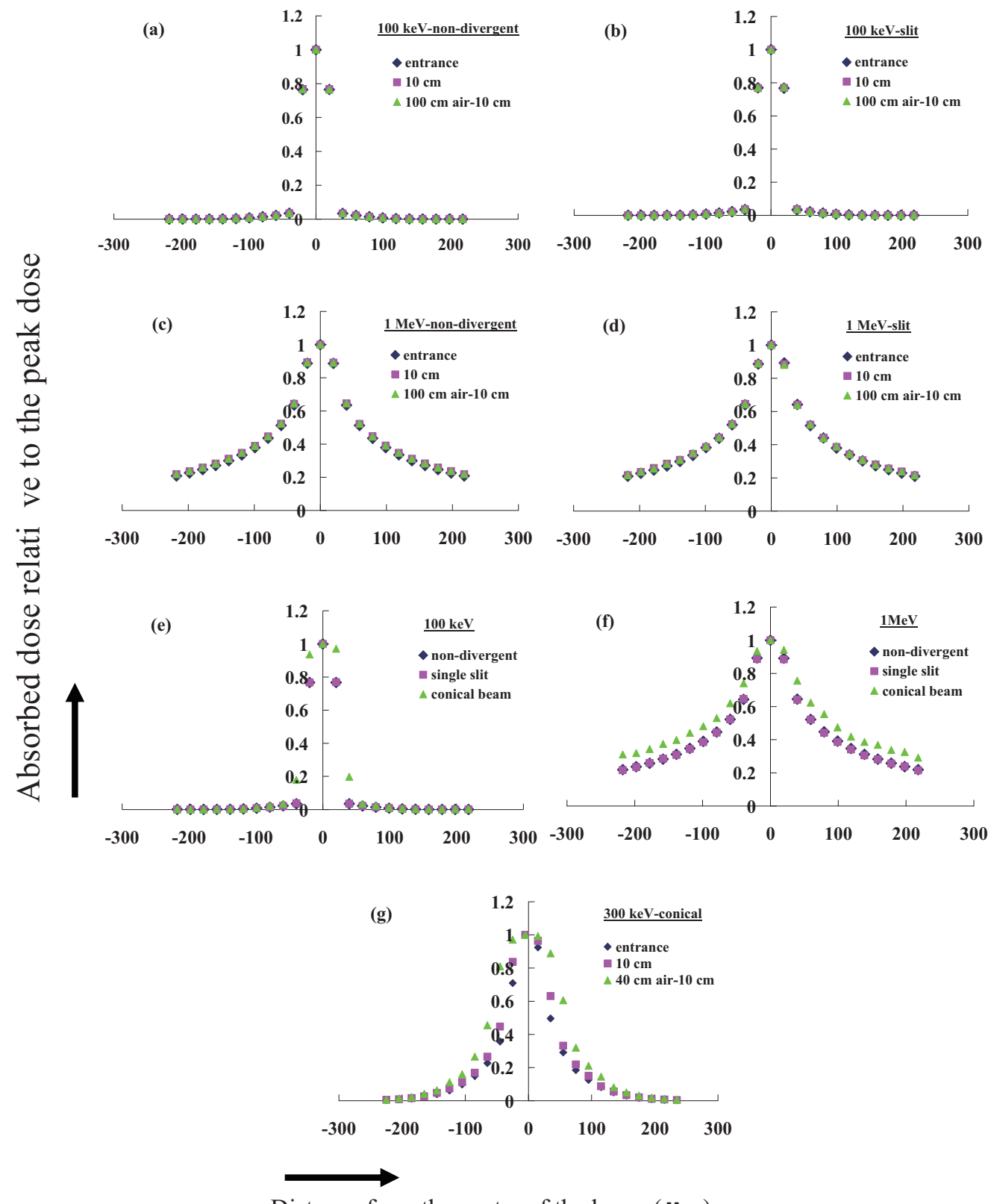

Distance from the center of the beam $(\boldsymbol{\mu} \mathrm{m})$

Fig. 3. Transverse dose distribution from the center of the beam. (a) $50 \mu \mathrm{m}$-wide non-divergent X-rays of $100 \mathrm{keV}$. (b) 100 $\mathrm{keV}$ non-divergent $\mathrm{X}$-rays passed through a $50 \mu \mathrm{m}$-single slit. (c) $50 \mu \mathrm{m}$-wide non-divergent $\mathrm{X}$-rays of $1 \mathrm{MeV}$. (d) $1 \mathrm{MeV}$ non-divergent X-rays passed through a $50 \mu \mathrm{m}$-single slit. (e) $100 \mathrm{keV}$ X-rays. (f) $1 \mathrm{MeV}$ X-rays. (g) $300 \mathrm{keV}$ conical X-rays (4 mrad divergence) passed through a $50 \mu \mathrm{m}$-single slit. Absorbed doses for (a) to (d), and (g) were calculated for $1 \mathrm{~cm}$ in depth at the entrance layer of the water (blue lozenge), at the $10 \mathrm{~cm}$ depth in water (pink square), and at the $10 \mathrm{~cm}$ depth in water after passing through $100 \mathrm{~cm}$ in air for (a) to (d), or $40 \mathrm{~cm}$ in air for (g) (green triangle). Absorbed doses for (e) and (f) were calculated at $10-11 \mathrm{~cm}$ in water for $50 \mu \mathrm{m}$-width non-divergent X-rays (blue lozenge), and non-divergent (pink square) or conical X-rays (green triangle) after passing through a $50 \mu \mathrm{m}$-single slit. (Colours are visible in the online version of the article; http://dx.doi.org/10.3233/XST-140434) 


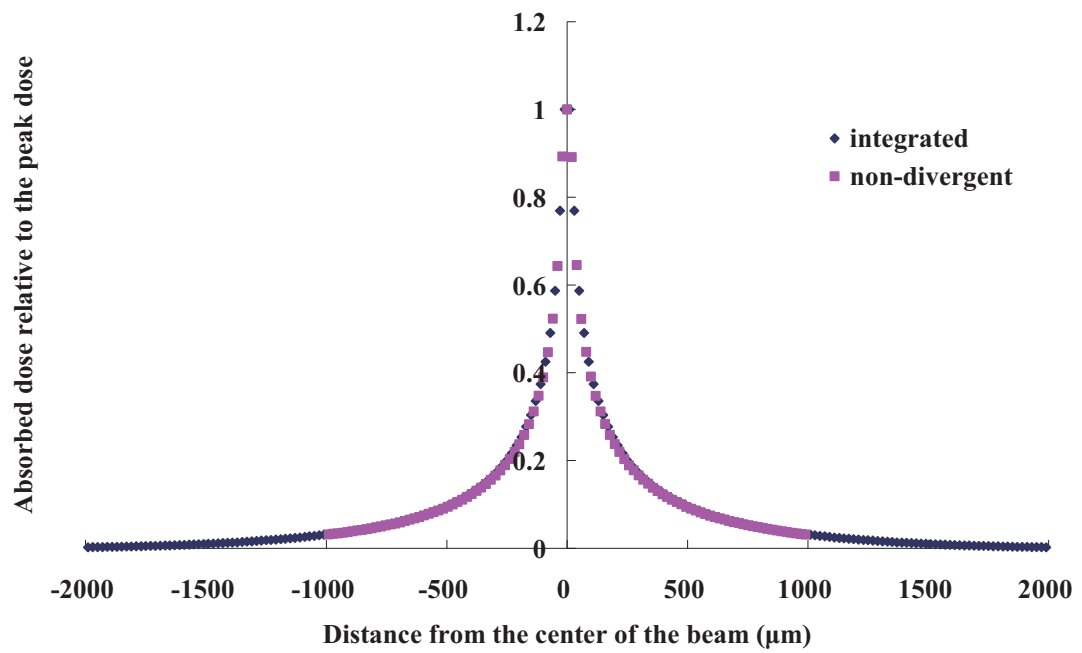

Fig. 4. Comparison of the transverse dose distribution for the absorbed dose at 10-11 $\mathrm{cm}$ in water. Absorbed dose of $50 \mu \mathrm{m}$-wide non-divergent $\mathrm{X}$-rays at an energy of $1 \mathrm{MeV}$ was integrated from calculated data for wide range one-side distribution (blue lozenge) and compared with directly calculated distribution (pink square). (Colours are visible in the online version of the article; http://dx.doi.org/10.3233/XST-140434)

transverse dose distribution was found when the absorbed dose was estimated with the water phantom positioned at the entrance, at $10 \mathrm{~cm}$ in depth, and at $10 \mathrm{~cm}$ in depth after passing through an air layer of $100 \mathrm{~cm}$ (Figs 3a to 3d). In addition, the distribution was independent of the presence of the tungsten slit (Figs 3e and 3f). However, when the X-ray beam was conical, the transverse distribution became broader (Figs $3 \mathrm{e}$ to $3 \mathrm{~g}$ ) and the width of the beam increased as the distance from the exit of tungsten slit increased (Fig. 3g).

To study the transverse dose distribution profile for five beams of $50 \mu \mathrm{m}$ wide and $500 \mu \mathrm{m}$ separation, $\pm 2 \mathrm{~mm}$ wide profile is required. Since PENELOPE code is limited to $\pm 1 \mathrm{~mm}$ wide profile for $20 \mu \mathrm{m}$ step distribution, wide range dose distribution was obtained as follows: one-side distribution from the beam center to $2 \mathrm{~mm}$ was calculated, then reversed it as for the reverse-side distribution from center to $-2 \mathrm{~mm}$, and integrated each other. In Fig. 4, this distribution profile for $1 \mathrm{MeV} \mathrm{X}$-rays was compared with the directly calculated dose distribution of non-divergent X-rays. It was confirmed that the estimation of wide-range distribution was possible by this integration method.

\subsection{Effect of the beam width on the transverse distribution}

Figure 5 shows the transverse dose distribution from the side boundary of the beam edge. The distribution was not affected by beam width $(20 \mu \mathrm{m}$ or $50 \mu \mathrm{m})$ even for the conical beam. However, when the $\mathrm{X}$-ray energy was $100 \mathrm{keV}$, a slight increase in the absorbed dose was found for the $50 \mu \mathrm{m}$ beam width.

\subsection{X-ray Energy dependence on the transverse dose distribution}

The energy dependence of the transverse dose distribution was estimated from the data between the center and a position at $2 \mathrm{~mm}$ from the center, by integrating the results to create a full profile as shown in Fig. 4. The integrated dose distributions were overlapped by shifting the beam center by $500 \mu \mathrm{m}$ to create 9 parallel beams of $50 \mu \mathrm{m}$ width with a $500 \mu \mathrm{m}$ center-to-center separation. Figure 6 shows the central portion of the results from $-300 \mu \mathrm{m}$ and $+700 \mu \mathrm{m}$. One of the characteristics of MRT is the 


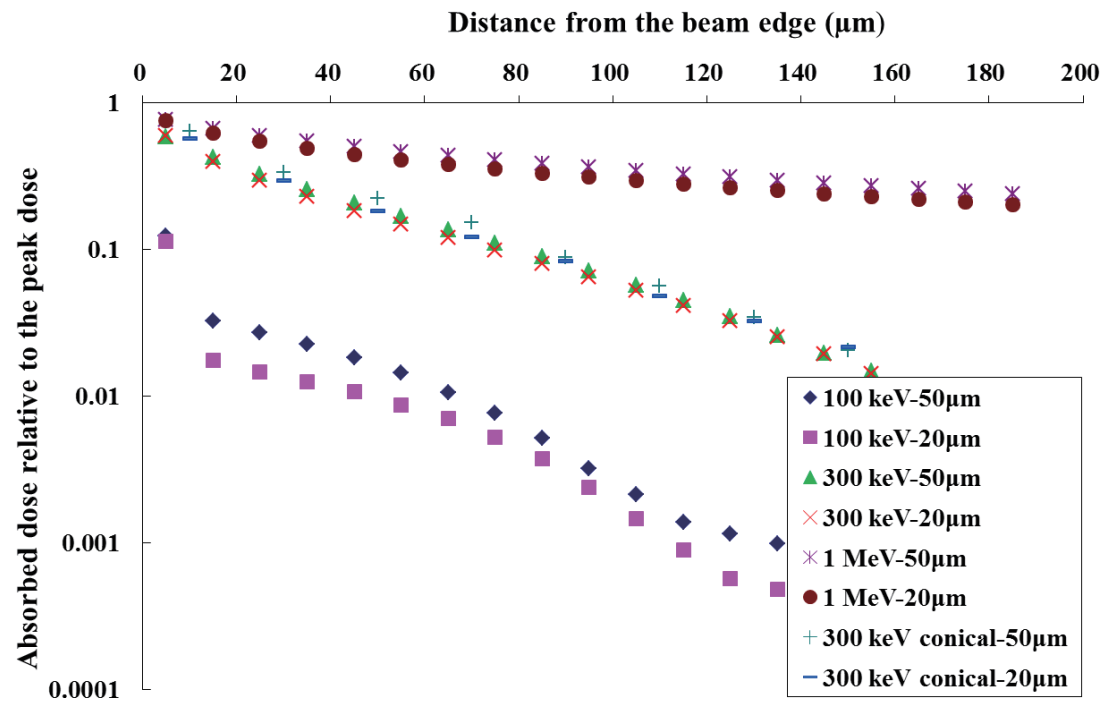

Fig. 5. Transverse distribution of absorbed dose from the beam edge relative to the peak dose. (Colours are visible in the online version of the article; http://dx.doi.org/10.3233/XST-140434)

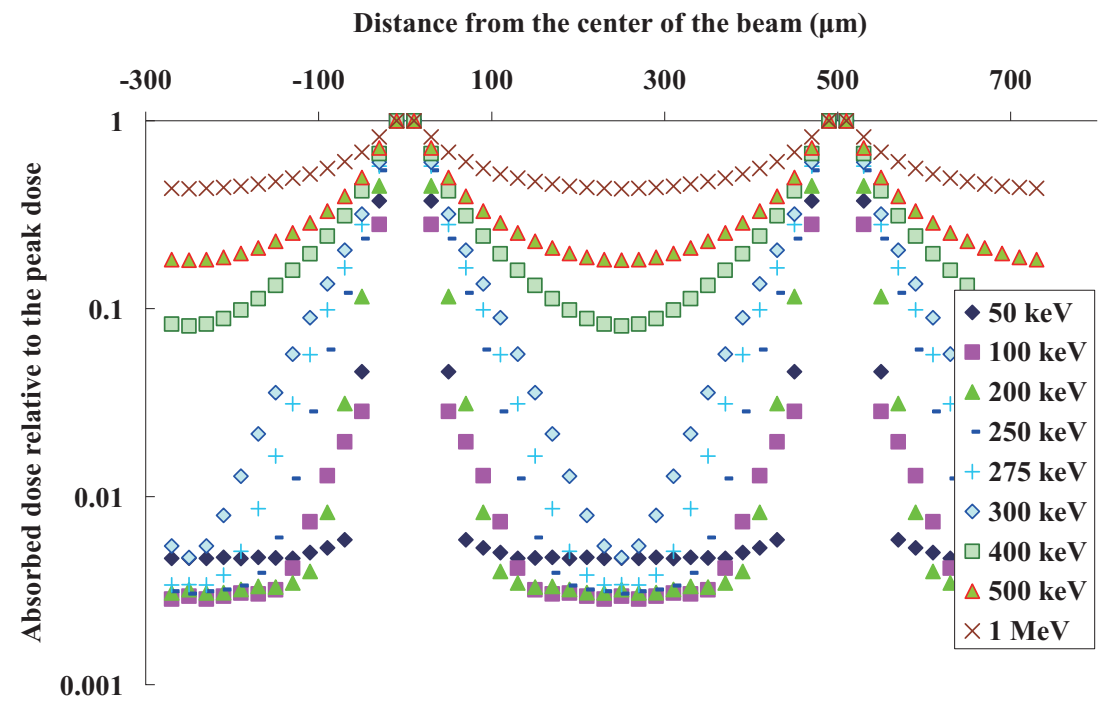

Fig. 6. Energy dependence of the transverse dose distribution on a log scale. The profile for the beam width of $50 \mu \mathrm{m}$ and the beam separation of $500 \mu \mathrm{m}$ was performed as described in the text and the central portion is shown in this figure. (Colours are visible in the online version of the article; http://dx.doi.org/10.3233/XST-140434)

level of the valley dose. Figure 6 shows that the valley dose and the dose in the I-zone increased with increasing X-ray energy. This increase was remarkable at the energy higher than $300 \mathrm{keV}$ probably due to the increased range of scattered X-rays and/or secondary X-rays and electrons. In contrast, it should be noted that relative valley dose was higher at $50 \mathrm{keV} \mathrm{X-rays} \mathrm{than} \mathrm{those} \mathrm{at} \mathrm{higher} \mathrm{energy} \mathrm{X-rays.} \mathrm{This}$ may be attributed to the small range of scattered X-rays and/or secondary X-rays in the case of $50 \mathrm{keV}$ $\mathrm{X}$-rays, at which the energy may be effectively deposited in the range of valley region. 
Table 1

Estimated values for each zone width

\begin{tabular}{ccc}
\hline Zone & $\begin{array}{c}\text { Absorbed dose } \\
(\mathrm{Gy})\end{array}$ & $\begin{array}{c}\text { Width } \\
(\mu \mathrm{m})\end{array}$ \\
\hline $\mathrm{P}$ & 300 & 25 \\
$\mathrm{I}$ & $6-300$ & $45-47.5$ \\
$\mathrm{~V}$ & $\leqslant 6$ & $80-85$ \\
\hline
\end{tabular}

Zone width at the surface of rat was estimated from Fig. 6 in the report by Nariyama et al. [27].

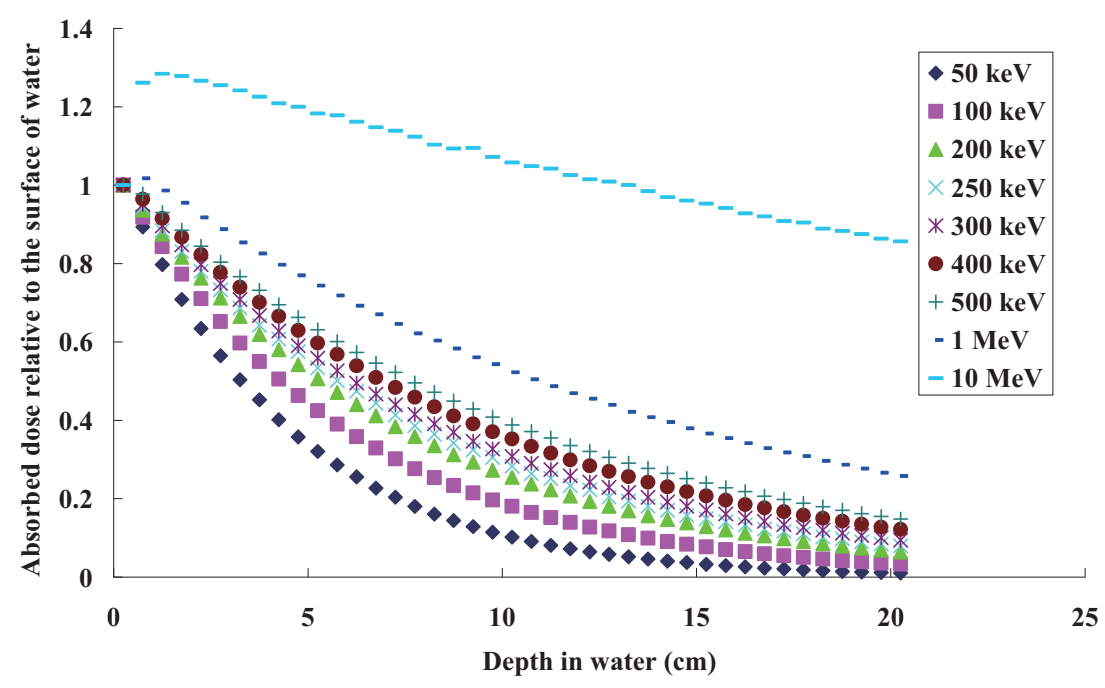

Fig. 7. Energy dependence of absorbed dose in a depth of water. The dose was estimated at a depth of $5 \mathrm{~mm}$ of water at the position shown in the abscissa. (Colours are visible in the online version of the article; http://dx.doi.org/10.3233/XST-140434)

\subsection{X-ray energy dependence of the absorbed dose at various depths in water}

The absorbed dose decreases as the depth of the tumor from the surface increases. Figure 7 shows the $\mathrm{X}$-ray energy dependence of the absorbed dose at various water depths. This decrease in the absorbed dose should be taken into account when MRT is applied to deep-seated tumors.

\subsection{Determination of I- and V-zone widths from the experimental results}

The sizes of the I- and V-zones in Fig. 2 were determined based on the experimental results of Kondoh et al. [26], in which Wistar rats bearing C6 glioma in the brain were irradiated with two orthogonal X-ray arrays at a peak dose of $\sim 300 \mathrm{~Gy}$ ( $25 \mu \mathrm{m}$ beam width and $200 \mu \mathrm{m}$ center-to-center beam separation). In their results, a remarkable increase in life span was observed with a median survival time of 51 days for treated rats, compared with 21 days for untreated rats. The dose distribution profile for the experiments was reported by Nariyama et al. [27]. Table 1 shows the values for each zone in Fig. 2, as estimated from the measured values in figure 6 in the report [27], based on the peak dose and beam width were $300 \mathrm{~Gy}$ and $25 \mu \mathrm{m}$, respectively and assumed that the dose in the valley region was $\leqslant 6$ Gy for the recovery of normal tissue. 
Table 2

Absorbed dose at $10-10.5 \mathrm{~cm}$ in water relative to the surface

\begin{tabular}{lccccccccccc}
\hline X-ray energy & $(\mathrm{keV})$ & 50 & 100 & 200 & 250 & 275 & 300 & 400 & 500 & 1000 & 10000 \\
\hline Absorbed dose relative to the surface & $(\%)$ & 10.2 & 18.1 & 25.5 & 28.3 & 29.9 & 30.8 & 35.2 & 38.8 & 52.2 & 105.8 \\
\hline
\end{tabular}

Absorbed dose relative to the surface was obtained from Fig. 7. Target was placed at a depth of $10 \mathrm{~cm}$ in water.

Table 3

$\mathrm{X}$-ray energy dependence of the peak dose at the target, I-zone width and beam separation when the peak dose at the surface is 300 Gy

\begin{tabular}{ccccc}
\hline $\begin{array}{c}\text { X-ray } \\
\text { energy } \\
(\mathrm{keV})\end{array}$ & $\begin{array}{c}\text { Peak dose } \\
\text { at the target } \\
(\mathrm{Gy})\end{array}$ & $\begin{array}{c}\text { I-zone } \\
\text { width } \\
(\mu \mathrm{m})\end{array}$ & 38 & $\begin{array}{c}20 \mu \mathrm{m} \\
(\mu \mathrm{m})\end{array}$ \\
\cline { 3 - 5 } & 30.6 & 44 & 176 & $\begin{array}{c}\text { Beam separation for the beam width of } \\
(\mu \mathrm{m})\end{array}$ \\
\hline 100 & 54.3 & 55 & 188 & 206 \\
200 & 76.5 & 96 & 210 & 218 \\
250 & 84.9 & 120 & 292 & 240 \\
275 & 89.7 & 149 & 340 & 322 \\
300 & 92.4 & 398 & 428 \\
\hline
\end{tabular}

Peak dose at the target was calculated using the data in Table 2. I-zone width was estimated from Fig. 6 as the distance between the beam edge and the point of absorption of $6 \mathrm{~Gy}$ in the surface. Difference in I-zone between the beam width of $20 \mu \mathrm{m}$ and $50 \mu \mathrm{m}$ was ignored. P-zone width: beam width. V-zone width: $80 \mu \mathrm{m}$. Beam separation $=$ P-zone width $+2 \times$ I-zone width + V-zone width. Target was placed at a depth of $10 \mathrm{~cm}$ in water.

Table 4

X-ray energy dependence of peak dose at the surface, I-zone width and beam separation when the peak dose to the target is 300 Gy

\begin{tabular}{ccccc}
\hline $\begin{array}{c}\text { X-ray } \\
\text { energy } \\
(\mathrm{keV})\end{array}$ & $\begin{array}{c}\text { Peak dose } \\
\text { at the surface } \\
(\mathrm{Gy})\end{array}$ & $\begin{array}{c}\text { I-zone } \\
\text { width } \\
(\mu \mathrm{m})\end{array}$ & - & \multicolumn{2}{c}{$\begin{array}{c}20 \mu \mathrm{m} \\
(\mu \mathrm{m})\end{array}$} & - & $\begin{array}{c}50 \mu \mathrm{m} \\
(\mu \mathrm{m})\end{array}$ \\
\cline { 4 - 5 } & 2941.2 & 116 & 332 & - \\
100 & 1657.5 & 80 & 260 & 362 \\
200 & 1176.5 & 129 & 358 & 290 \\
250 & 1060.1 & 160 & 420 & 388 \\
275 & 1003.3 & 200 & 500 & 450 \\
300 & 974.0 & 530 & \\
\hline
\end{tabular}

Peak dose at the surface was calculated using the data in Table 2. I-zone width was estimated from Fig. 6 as the distance between the beam edge and the point of absorption of $6 \mathrm{~Gy}$ on the surface. Difference in I-zone between the beam width of $20 \mu \mathrm{m}$ and $50 \mu \mathrm{m}$ was ignored. P-zone width: beam width. V-zone width: $80 \mu \mathrm{m}$. Beam separation $=\mathrm{P}$-zone width $+2 \times \mathrm{I}$-zone width + $\mathrm{V}$-zone width. Target was placed at a depth of $10 \mathrm{~cm}$ in water.

\subsection{X-ray dose for MRT to the deep-seated tumors in various $X$-ray energies}

Table 2 shows the numerical data of Fig. 7 for the energy dependence of the absorbed dose relative to the surface when the tumor is present at a depth of $10 \mathrm{~cm}$ from the surface. When the peak dose at the surface is $300 \mathrm{~Gy}, 10 \mathrm{MeV} \mathrm{X}$-rays are required for the delivery of $\sim 300 \mathrm{~Gy}(105.8 \%)$ onto the tumor. At an X-ray energy of $250 \mathrm{keV}$, only $\sim 85 \mathrm{~Gy}(28.3 \%)$ will be delivered to the tumor. If we maintain a peak dose of $300 \mathrm{~Gy}$ at the tumor located at a $10 \mathrm{~cm}$ depth, the peak dose at the surface must be increased to more than $1000(=300 / 0.299)$ Gy with an X-ray energy of $275 \mathrm{keV}$. The data in Table 2 were used for the calculation of absorbed dose in Tables 3 and 4.

Tables 3 and 4 show the energy dependence of the estimated peak dose, I-zone width, and beam separation, at a beam width of $20 \mu \mathrm{m}$ or $50 \mu \mathrm{m}$ and a peak dose of $300 \mathrm{~Gy}$. Table 3 shows these parameters 
Table 5

Collected results for MRT of brain tumors irradiated with two orthogonal or bidirectional beams

\begin{tabular}{|c|c|c|c|c|c|c|c|}
\hline \multirow[t]{2}{*}{$\begin{array}{l}\text { Peak dose } \\
\text { at the surface } \\
\text { (Gy) }\end{array}$} & \multirow[t]{2}{*}{$\begin{array}{l}\text { Beam } \\
\text { width } \\
(\mu \mathrm{m})\end{array}$} & \multirow[t]{2}{*}{$\begin{array}{l}\text { Beam } \\
\text { separation } \\
(\mu \mathrm{m})\end{array}$} & \multirow[t]{2}{*}{$\begin{array}{c}\text { Increase in } \\
\text { median survival time } \\
\text { (days) }\end{array}$} & \multirow[t]{2}{*}{ Reference } & \multicolumn{3}{|c|}{$\begin{array}{l}\text { Beam separation }(\mu \mathrm{m}) \text { based on the present } \\
\text { assumption for the peak dose on the surface } \\
\text { at an X-ray energy of }\end{array}$} \\
\hline & & & & & $50 \mathrm{keV}$ & $100 \mathrm{keV}$ & $250 \mathrm{keV}$ \\
\hline 312.5 & 25 & 100 & $20 \rightarrow 96$ & [7] & 182 & 197 & 298 \\
\hline 625 & 25 & 100 & $20 \rightarrow 139$ & [7] & 191 & 259 & 333 \\
\hline 350 & 75 & 211 & significant increase & [18] & 234 & 259 & 353 \\
\hline 320 & 75 & 211 & $18 \rightarrow 40$ & [19] & 232 & 250 & 349 \\
\hline 480 & 50 & 211 & $18 \rightarrow 53$ & [19] & 213 & 263 & 340 \\
\hline 860 & 25 & 211 & $18 \rightarrow 18$ & [19] & 194 & 280 & 349 \\
\hline 480 & 50 & 200 & $19 \rightarrow 35.5$ & [23] & 213 & 263 & 340 \\
\hline
\end{tabular}

at the surface and Table 4 shows these parameters at a tumor site at a depth of $10 \mathrm{~cm}$ in water based on the V-zone (absorbed dose $\leqslant 6$ Gy at the surface) width to be $80 \mu \mathrm{m}$.

When the peak dose at the surface is set to $300 \mathrm{~Gy}$, the dose delivered to the tumor at a depth of $10 \mathrm{~cm}$ from the surface is calculated to be less than $100 \mathrm{~Gy}$ for an X-ray energy below $300 \mathrm{keV}$ (Table 3). In contrast, if MRT requires a peak dose of $300 \mathrm{~Gy}$ at the tumor, the dose at the surface must be as high as $1000 \mathrm{~Gy}$ at an X-ray energy of $300 \mathrm{keV}$ (Table 4) and $1250 \mathrm{~Gy}$ at an energy between 100 and $200 \mathrm{keV}$. Since Slatkin et al. [6] demonstrated that brain tissue is apparently normal in all cases at an in-beam skin dose of $\leqslant 625 \mathrm{~Gy}$ for MRT and in most cases at $\leqslant 1250 \mathrm{~Gy}$, the tolerable level of skin-entrance dose is probably in the range of $625-1250 \mathrm{~Gy}$. In addition, the required peak dose for the treatment could be less than $300 \mathrm{~Gy}$, although the optimum peak dose remains to be studied.

Thus, in combination with the results indicated in Section 3.3, we conclude that the optimum energy for MRT is in the range of $100-300 \mathrm{keV}$. The results indicate that the tolerable surface dose must be determined for the successful treatment of MRT for deep-seated tumors.

\section{Discussion}

\subsection{Rational for the V-zone to be $\leqslant 6$ Gy}

Since one of the characteristic advantages of MRT over conventional radiation therapy may be in the efficient recovery rate of normal tissue, resulting in highly selective killing of tumor cells, we based on the knowledge that the recovery of normal healthy tissue is a critical factor. Thus, we assumed a V-zone for the recovery of normal tissue and an absorbed dose in the V-zone of $\leqslant 6$ Gy which is tolerable for normal skin to the acute effects of radiation [28], although the upper limit for this value remains to be determined.

\subsection{Importance of the present method}

Table 5 shows a summary of the reported results based on irradiation with two orthogonal or bidirectional beams. These results were obtained from animal studies in which tumors were seated close to the surface. In Table 5, estimated values of beam separation according to the current assumptions are also included for the comparison. The beam separations in all reported successful experiments were smaller than the estimated values. The results suggest that either a valley dose greater than 6 Gy may be tolerable by normal tissue or the distance of the V-zone may be smaller than $80 \mu \mathrm{m}$. In addition, the results 
obtained by Laissue et al. [7] were the most effective for the treatment. The reason may be due to the low X-ray energy since in their case the mean energy was approximately $50 \mathrm{keV}$ and $90 \%$ of the beam was in the range of 32 to $131 \mathrm{keV}$, while X-rays from other reports had a mean at the energy range of 90-100 keV and most were in the range of 50-350 keV. As shown in Fig. 6, higher energy X-rays affect more to an increased range of I-zone. Therefore, the effective treatment by Laissue et al. [7] could be explained by the smaller I-zone and wider valley region compared with other experiments. Even in their case, the valley dose must be higher than $6 \mathrm{~Gy}$ because the beam separations in their experiments are smaller than the estimated value for $50 \mathrm{keV}$ X-rays as shown in Table 5. Based on these considerations, the current method was in good agreement with the experimental results for animal tumors seated close to the surface and is to be supported for the estimation of doses for deep seated tumors. These results give the very important knowledge for the precise evaluation of dose and the distance of the V-zone.

\subsection{Parameter optimization for irradiation program}

The following parameters remain to be clarified for the optimization of an irradiation program: (1) lower limit of peak dose, (2) upper limit of valley dose tolerable for normal tissue recovery, and (3) optimum V-zone distance. In addition, for the effective treatment, the tumors should not be moved during irradiation. For this purpose, intense, short pulsed X-rays are required. Since nerve motion is greater than $0.1 \mathrm{~mm}$ in one cardiac-cycle [29], the required irradiation-time duration should be less than $1 \mathrm{~ms}$ such that movement of the tumors is limited to less than $10 \mu \mathrm{m}$, which keeps the structure of the microbeams at 20-50 $\mu \mathrm{m}$ in width. To fulfill this condition, an intense, pulsed X-ray source driven by a laser [30-32] or accelerator [33-35] may be a candidate for a future X-ray source along with synchrotron radiation.

\subsection{Potential advantages of MRT}

The mechanism for the selective killing of tumor cells should be attributed to the selective damage in the tumor vessels compared with those for normal tissue [36-39]. This is completely different from the conventional treatment method which aims at the selective killing of tumor cells. Thus, potential advantages of an MRT over a conventional X-ray treatment method are: (1) Patient may obtain relief from a heavy treatment load, because the treatment is only administered once in two directions of irradiation, which is quite different from conventional radiation therapy; (2) Positioning the patient may be simpler because the treatment area can be decided easily as the area including the tumor site and is not as critical as in the conventional method; (3) Repeated treatments may be possible; and in addition, (4) The use of gold nanoparticles as an anti-angiogenic sensitizer [40] may be much more effective for the treatment by the dose enhancement on tumor capillary vessels. The rationale for the third advantage is as follows: recovered normal cells were exposed to a very low level of X-rays, since all of the in-beam (P-zone) cells and many of I-zone cells should be dead. Therefore, only a small fraction of the normal cells in the treated area would have memory of the X-ray exposure. In contrast, in the conventional method, most normal cells in the irradiated area would have X-ray exposures as high as the accumulated dose of the total treatment. Although these possibilities remain to be clarified by future animal studies, the current results strongly suggest the potential of MRT for human treatment.

\section{Acknowledgements}

We thank Professor Ryosuke Kodama, Graduate School of Engineering, Osaka University, Japan for his useful comments. This work was partially supported by the Japan Society for the Promotion of Science, Grant-in-Aid for Scientific Research (B), KAKENHI (21340066). 


\section{References}

[1] E. Bräuer-Krisch, R. Serduc, E.A. Siegbahn, G. Le Duc, Y. Prezado, A. Bravin, H. Blattmann and J.A. Laissue, Effects of pulsed, spatially fractionated, microscopic synchrotron X-ray beams on normal and tumoral brain tissue, Mutation Res 704 (2010), 160-166.

[2] D.J. Anschel, A. Bravin and P. Romanelli, Microbeam radiosurgery using synchrotron-generated submillimetric beams: A new tool for the treatment of brain disorders, Neurosurg Rev 34 (2011), 133-142.

[3] W. Zeman, H.J. Curtis and C.P. Baker, Histopathologic effect of high-energy-particle microbeams on the visual cortex of the mouse brain, Radiat Res 15 (1961), 496-514.

[4] W.E. Straile and H.B. Chase, The use of elongate microbeams of X-rays for simulating the effects of cosmic rays on tissues: A study of wound healing and hair follicle regeneration, Radiat Res 18 (1963), 65-75.

[5] D.N. Slatkin, P. Spanne, F.A. Dilmanian and M. Sandborg, Microbeam radiation therapy, Med Phys 19 (1992), 13951400.

[6] D.N. Slatkin, P. Spanne, F.A. Dilmanian, J.-O. Gebbers and J.A. Laissue, Subacute neuropathological effects of microplanar beams of x-rays from a synchrotron wiggler, Proc Natl Acad Sci USA 92 (1995), 8783-8787.

[7] J.A. Laissue, G. Geiser, P. Spanne, F.A. Dilmanian, J.-O. Gebbers, M. Geiser, X.-Y. Wu, M.S. Makar, P.L. Micca, M.M. Nawrocky, D.D. Joel and D.N. Slatkin, Neuropathology of ablation of rat gliosarcomas and contiguous brain tissues using a microplanar beam of synchrotron-wiggler-generated X rays, Int J Cancer 78 (1998), 654-660.

[8] J.A. Laissue, N. Lyubimova, H.-P. Wagner, D.W. Archer, D.N. Slatkin, M.D. Michiel, C. Nemoz, M. Renier, E. Brauer, P.O. Spanne, J.-O. Gebbers, K. Dixon and H. Blattmann, Microbeam radiation therapy, Proc. SPIE 3770 (1999), 38-45.

[9] P.M. Schweizer, P. Spanne, M.D. Micheil, U. Jauch, H. Blattmann and J.A. Laissue, Tissue lesions caused by microplanar beams of synchrotron-generated X-rays in Drosophila melanogaster, Int J Radiat Biol 76 (2000), 567-574.

[10] F.A. Dilmanian, G.M. Morris, G. Le Duc, X. Huang, B. Ren, T. Bacarian, J.C. Allen, J. Kalef-Ezra, I. Orion, E.M. Rosen, T. Sandhu, P. Sathe, X.Y. Wu, Z. Zhong and H.L. Shivaprasad, Response of avian embryonic brain to spatially segmented X-ray microbeams, Cell Mol Biol 47(2001), 485-493.

[11] J.A. Laissue, H. Blattmann, M.D. Michiel, D.N. Slatkin, N. Lyubimova, R. Guzman, W. Zimmermann, S. Birrer, T. Bley, P. Kircher, R. Stettler, R. Fatzer, A. Jaggy, H.M. Smilowitz, E. Bruer, A. Bravin, G. Le Duc, C. Nemoz, M. Renier, W. Thomlinson, J. Stepanek and H.-P. Wagner, The weanling piglet cerebellum: A surrogate for tolerance to MRT (microbeam radiation therapy) in pediatric neuro-oncology, Proc SPIE 4508 (2001), 65-73.

[12] N. Zhong, G.M. Morris, T. Bacarian, E.M. Rosen and F.A. Dilmanian, Response of rat skin to high-dose unidirectional X-ray microbeams: A histological study, Radiat Res 160 (2003), 133-142.

[13] F.A. Dilmanian, T.M. Button, G. Le Duc, N. Zhong, L.A. Peña, J.A.L. Smith, S.R. Martinez, T. Bacarian, J. Tammam, B. Ren, P.M. Farmer, J. Kalef-Ezra, P.L. Micca, M.M. Nawrochy, J.A. Niederer, F.P. Recksiek, A. Fuchs and E.M. Rosen, Response of rat intracranial 9L gliosarcoma to microbeam radiation therapy, Neuro-Oncol 4 (2002), 26-38.

[14] F.A. Dilmanian, G.M. Morris, N. Zhong, T. Bacarian, J.F. Hainfeld, J. Kalef-Ezra, L.J. Brewington, J. Tammam and E.M. Rosen, Murine EMT-6 carcinoma: High therapeutic efficacy of microbeam radiation therapy, Radiat Res 159 (2003), 632-641.

[15] H.M. Smilowitz, H. Blattmann, E. Bräuer-Krisch, A. Bravin, M.D. Michiel, J.-O. Gebbers, A.L. Hanson, N. Lyubimova, D.N. Slatkin, J. Stepanek and J.A. Laissue, Synergy of gene-mediated immunoprophylaxis and microbeam radiation therapy for advanced intracerebral rat 9L gliosarcomas, J Neuro-Oncol 78 (2006), 135-143.

[16] M. Miura, H. Blattmann, E. Bräuer-Krisch, A. Bravin, A.L. Hanson, M.M. Nawrocky, P.L. Micca, D.N. Slatkin and J.A. Laissue, Radiosurgical palliation of aggressive murine SCCVII squamous cell carcinomas using synchrotron-generated X-ray microbeams, Br J Radiol 79 (2006), 71-75.

[17] P. Regnard, G. Le Duc, E. Bräuer-Krisch, I. Troprès, E.A. Siegbahn, A. Kusak, C. Clair, H. Bernard, D. Dallery, J.A. Laissue and A. Bravin, Irradiation of intracerebral 9L gliosarcoma by a single array of microplanar x-ray beams from a synchrotron: balance between curing and sparing, Phys Med Biol 53 (2008), 861-878.

[18] E. Schültke, B.H.J. Juurlink, K. Ataelmannan, J. Laissue, H. Blattmann, E. Bräuer-Krisch, A. Bravin, J. Minczewska, J. Crosbie, H. Taherian, E. Frangou, T. Wysokinsky, L.D. Chapman, R. Griebel and D. Fourney, Memory and survival after microbeam radiation therapy, Eur J Radiol 68S (2008), S142-S146.

[19] R. Serduc, A. Bouchet, E. Bräuer-Krisch, J.A. Laissue, J. Spiga, S. Sarun, A. Bravin, C. Fonta, L. Renaud, J. Boutonnat, E.A. Siegbahn, F. Estève and G. Le Duc, Synchrotron microbeam radiation therapy for rat brain tumor palliationinfluence of the microbeam width at constant valley dose, Phys Med Biol 54 (2009), 6711-6724.

[20] R. Serduc, E. Bräuer-Krisch, A. Bouchet, L. Renaud, T. Brochard, A Bravin, J.A. Laissue and G. Le Duc, First trial of spatial and temporal fractionations of the delivered dose using synchrotron microbeam radiation therapy, J Synchrotron Radiat 16 (2009), 587-590.

[21] J.C. Crosbie, R.L. Anderson, K. Rothkamm, C.M. Restall, L. Cann, S. Ruwanpura, S. Meachem, N. Yagi, I. Svalbe, R.A. Lewis, B.R.G. Williams and P.A.W. Rogers, Tumor cell response to synchrotron microbeam radiation therapy differs markedly from cells in normal tissues, Int J Radiat Oncol Biol Phys 77 (2010), 886-894. 
[22] A. Uyama, T. Kondoh, N. Nariyama, K. Umetani, M. Fukumoto, K. Shinohara and E. Kohmura, A narrow beam microbeam is more effective for tumor growth suppression than a wide microbeam: An in vivo study using implanted human glioma cells, J Synchrotron Radiat 18 (2011), 671-678.

[23] A. Bouchet, A. Boumendjel, E. Khalil, R. Serduc, E. Bräuer, E.A. Siegbahn, J.A. Laissue and J. Boutonnat, Chalcone JAI-51 improves efficacy of synchrotron microbeam radiation therapy of brain tumors, J Synchrotron Radiat 19 (2012), 478-482.

[24] Y. Prezado, S. Thengumpallil, M. Renier and A. Bravin, X-ray energy optimization in minibeam radiation therapy, Med Phys 36 (2009), 4897-4902.

[25] F. Salvat, J.M. Fernández-Varea and J. Sempau, "PENELOPE-2008: A code system for Monte Carlo simulation of electron and photon transport” (OECD Nuclear Energy Agency, Issy-les-Moulineaux, France), 2008.

[26] T. Kondoh, K. Shinohara, M. Fukumoto, N. Nariyama and K. Umetani, Experimental study for cancer treatment using synchrotron radiation (in Japanese), Ionizing Radiat 39 (2013), 51-53.

[27] N. Nariyama, T. Ohigashi, K. Umetani, K. Shinohara, H. Tanaka, A. Maruhashi, G. Kashino, A. Kurihara, T. Kondoh, M. Fukumoto and K. Ono, Spectromicroscopic film dosimetry for high-energy microbeam from synchrotron radiation, Applied Radioat. Isotopes 67 (2009), 155-159.

[28] T. Sugahara and Y. Ujeno, Fundamentals of Radiology (in Japanese), 4th ed. Japan, Kinpodo, 1979.

[29] M. Labrousse, G. Hossu, G. Calmon, A. Chays, J. Felblinger and M. Braun, In vivo characterization of the vestibulocochlear nerve motion by MRI, Neuroimage 59 (2012), 943-949.

[30] K. Shinohara, H. Nakano, N. Miyazaki, M. Tago and R. Kodama, Effects of single-pulse ( $\leqslant 1 \mathrm{ps})$ X-rays from laserproduced plasmas on mammalian cells, J Radiat Res 45 (2004), 509-514.

[31] V. Malka, J. Faure, Y.A. Gauduel, E. Lefebvre, A. Rousse and K.T. Phuoc, Principles and applications of compact laserplasma accelerators, Nature Phys 4 (2008), 447-453.

[32] S. Cipiccia, M.R. Islam, B. Ersfeld, R.P. Shanks, E. Brunetti, G. Vieux, X. Yang, R.C. Issac, S.M. Wiggins, G.H. Welsh, M.-P. Anania, D. Maneuski, R. Montgomery, G. Smith, M. Hoek, D.J. Hamilton, N.R.C. Lemos, D. Symes, P. Rajeev, V.O. Shea, J.M. Dias and D.A. Jaroszynski, Gamma-rays from harmonically resonant betatron oscillations in a plasma wake, Nature Phys 7 (2011), 867-871.

[33] K. Sakaue, M. Washio, S. Araki, M. Fukuda, Y. Higashi, Y. Honda, T. Omori, T. Taniguchi, N. Terunuma, J. Urakawa and N. Sasao, Observation of pulsed x-ray trains produced by laser-electron Compton scatterings, Rev Sci Instrum 80 (2009), 123304-1-123304-7.

[34] R. Kuroda, H. Toyokawa, M. Yasumoto, H. Ikeura-Sekiguchi, M. Koike, K. Yamada, T. Yanagida, T. Nakajyo, F. Sakai and K. Mori, Quasi-monochromatic hard X-ray source via laser Compton scattering and its application, Nucl Instrum Methods Phys Res A 637 (2011), 5183-5186.

[35] K. Sakaue, T. Aoki, M. Washio, S. Araki, M. Fukuda, N. Terunuma and J. Urakawa, First refraction contrast imaging via laser-Compton scattering X-ray at KEK, International Workshop on X-ray and Neutron Phase Imaging with Gratings AIP Conf Proc 1466 (2012), 272-277.

[36] R. Serduc, P. Vèrant, J.-C. Vial, R. Farion, L. Rocas, C. Rèmy, T. Fadlallah, E. Brauer, A. Bravin, J. Laissue, H. Blattmann and B. Sanden, In vivo two-photon microscopy study of short-term effects of microbeam irradiation on normal mouse brain microvasculature, Int J Radiat Oncol Biol Phys 64 (2006), 1519-1527.

[37] B. van Der Sanden, E. Bräuer-Krisch, E.A. Siegbahn, C. Ricard, J.-C. Vial and J. Laissue, Tolerance of arteries to microplanar X-ray beams, Int J Radiat Oncol Biol Phys 77 (2010), 1545-1552.

[38] A. Bouchet, B. Lemasson, G. Le Duc, C. Maisin, E. Bräuer-Krisch, E.A. Siegbahn, L. Renaud, E. Khalil, C. Rèmy, C. Poillot, A. Bravin, J.A. Laissue, E.L. Barbier and R. Serduc, Preferential effect of synchrotron microbeam radiation therapy on intracerebral 9L gliosarcoma vascular networks, Int J Radiat Oncol Biol Phys 78 (2010), 1503-1512.

[39] S. Sabatasso, J.A. Laissue, R. Hlushchuk, W. Graber, A. Bravin, E. Bräuer-Krisch, S. Corde, H. Blattmann, G. Gruber and V. Djonov, Microbeam radiation-induced tissue damage depends on the stage of vascular maturation, Int J Radiat Oncol Biol Phys 80 (2011), 1522-1532.

[40] E. Amato, A. Italiano, S. Leotta, S. Pergolizzi and L. Torrisi, Monte Carly study of the dose enhancement effect of gold nanoparticles during X-ray therapies and evaluation of the anti-angiogenic effect on tumour capillary vessels, $J X$-Ray Sci and Technol 21 (2013), 237-247. 